\title{
The "SENANG" training to increase the subjective well-being of adolescent students
}

Dewanto, Aji Cokro $\bowtie$

Faculty of Psychology, Universitas Gadjah Mada, Indonesia (cokrodewanto@yahoo.com)

Alsa, Asmadi

Faculty of Psychology, Universitas Gadjah Mada, Indonesia (asmalsa@ugm.ac.id)

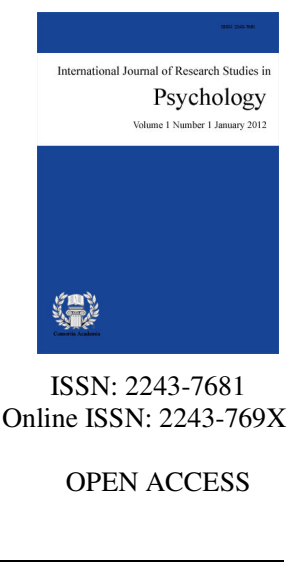

Received: 21 November 2015

\section{Abstract}

The educational problems indicate that a number of senior high school students feel discomfortable while studying at school. At adolescent students, the problems are generally caused by the negative evaluation of their daily activities, particularly in the school area that appear the negative affectation. Hence, this research aimed to find out the effectiveness of the "SENANG" training program in order to increase the subjective well-being of adolescent students. This quasi experiment was conducted by using the untreated control group design with dependent pretest and posttest samples using double pretest. The technique of collecting data was done by using Subjective Well-Being of Adolescent Students Scale. The subjects of this research were 18 adolescent students at range of age 15-17 years old with subjective well-being score in medium category. The results showed that the subjective well-being of adolescent students at the experimental group was higher than the control group after the intervention. The "SENANG" training gave a contribution to the subjective well-being of adolescent students up to $78.4 \%$.

Keywords: subjective well-being; rational-emotive approach; adolescent students; rational-emotive approach based training; quasi experiment 


\section{The "SENANG" training to increase the subjective well-being of adolescent students}

\section{Introduction}

Indonesia is a country which pays attention to the prosperity of its populations as stated on the preamble of the Constitution of the Republic of Indonesia that "....The Government of the Republic of Indonesia which protects all of Indonesian people and all the spilled blood throughout to advance the general prosperity." Surely, the prosperity in this case is included of the prosperity on education field. However, Konu and Rimpela (2002) stated that the prosperity often separated from the curriculum. It is proved by the preference of the education quality increase that focused on the addition of cognitive responsibility to the students, so that the students' well-being at school is lack of attention (Siswoyo, 2007). One phenomenon of the low of the students' well-being can be seen from the low percentage of the students who are continuing to take the next higher education level. Sarjana (2005) stated that one of the factors is the intrinsic motivation of the students, which indicates the students do not consider that school is fun.

Earlier study which was conducted by the researchers in a private SMK (vocational senior high school) in Yogyakarta also showed that the school's greatest problem was the number of students who lack enthusiasm and enjoyment of their daily activities at school, so that it gave an impact to the high frequency of belated behavior and truancy. The earlier survey which was done to 52 students of class X of a public SMA (senior high school) in Yogyakarta indicated that $92 \%$ of the students considered the need of attending school, but the problem was $85 \%$ of the students judged the minimum facilities that provided by the school. It indicated the students' dissatisfaction of the learning condition at school. The survey also showed that $60 \%$ respondents regarded themselves should be in the better school. Affectively, $10 \%$ of the students used to feel stress with the learning condition at school.

\subsection{Adolescent student}

Dryfoos' research (in Roeser, 2008) showed that at adolescent students, the low of school's bondage can cause more extreme behaviors, such as emotional distress, and on the range of three years later can provide behavior problems like drugs consumption, delinquency, pregnancy before married, and schooling strike. The adolescents with the low subjective well-being tend to be passive of involving themselves to the activities at school like extracurricular (Utami, 2009), which impacts to their disabilities to enjoy the experiences at school. Further, the research conducted by Huebner and Diener (2008) found out that the unhappy adolescents with their experiences at school tend to get difficulty in adapting to the several of life challenges and it causes problems such as suicide desire, psychosomatic, and depression.

Adolescent students have their own challenge. Adolescence is a transition period of time from childhood to adulthood, so there will be the changes of the emotion, cognitive, and behavior that influence to the subjective well-being (Yadav, 2011). Santrock (2007) also explained that adolescents have owned perspective taking which is evolving. It is an ability to observe or notice something from other people's point of view and to understand his/her own thoughts and feelings. This matter causes adolescents become very sensitive to what people think about them. Adolescents also have egocentric cognitive development. Elkind (in Santrock, 2007) stated that there are two types of adolescent egocentric:

a. The imaginary audience - a part adolescent egocentric which adolescents demand a seeking attention behavior. Effort to be looked excellent. They believe that they are the main actor and the others are only viewers.

b. The personal fable - a part of adolescent egocentric which adolescents consider themselves unique, and untouchable. Adolescents believe that their uniqueness make people cannot fully understand their feelings. 
The "SENANG" training to increase the subjective well-being of adolescent students

As the consequence, adolescents often create story about themselves that detached from the reality.

Adolescence is a transition period of time from childhood to adulthood, so there will be the changes of the emotion, cognitive, and behavior that influence to the subjective well-being (Yadav, 2011). In the process, adolescents tend to be dissatisfied to themselves, criticize themselves, and compare themselves to the others. But actually, by accepting that everyone is a kind person, in all the conditions, so an individual can be more positive (Ellis, in Chamberlain, 1999).

Adolescents who are in the transition of educational stage tend to dissatisfied to their schools. Santrock (2007) states that the periods of school transition tend to appear top-dog phenomenon, that is the condition change from a senior student who has the greatest influence on his/her stage, then becoming a fresh junior student and has not influence on the next educational stage. The student's experience in this case has been shaped since entering class VII (the first grade of junior high school). It can be said that the transitions from elementary school to junior high school and from junior high school to senior high school have similar challenges for the students, especially the students of class X of Senior High School.

\subsection{Subjective well-being on adolescent student}

Subjective well-being is an evaluation result of someone toward his/her life cognitively and affectively (Diener \& Lucas, 2000). That evaluation can be evaluated in particular domain (Diener, 1984; Triandis, 2000), which in this case is the student's life at school. It is related to the statement of Shoshani and Steinmetz (2013) that the subjective well-being is important to be grown up in school context because there is a positive correlation between the subjective well-being of the students and the school's bondage.

Subjective well-being has two aspects; they are cognitive aspect and affective aspect (Diener \& Biswas-Diener, 2003; Vazquez, Hervas, Rahona, \& Gomez, 2009). Cognitive aspect of subjective well-being is in a form of the evaluation of life satisfaction (Diener \& Biswas-Diener, 2003; Larsen \& Eid, 2008; Proctor, Linley, \& Maltby, 2009; Kim \& Tov, 2011). That life satisfaction can be evaluated in general or can be seen in more specific domains such as job or family (Diener, 1984; Diener, Suh, \& Oishi, 1997; Triandis, 2000). Affective aspect of subjective well-being is divided into two; they are positive and negative affectations (Diener, Suh, \& Oishi, 1997). Schimmack (2008) explained that the correlation of positive affectation and negative affectation approximates to zero. It means that someone with high positive affectation does not mean have low negative affectation. Measuring the subjective well-being affectively is done by comparing the frequencies of positive affectation and negative affectation (Larsen \& Eid, 2008). Someone is said having high subjective well-being when s/he experiences the positive affectation more often or stronger than the negative affectation (Kim \& Tov, 2011).

According to Focus Group Discussion had done by the researchers with 10 students of class XII of a public Senior High School in Yogyakarta, it was obtained six indicators that considerable often influence to the subjective well-being of adolescent students at school: 1) academic condition of the students, 2) relationship with the friends, 3) relationship to the teachers, 4) activities at school, 5) facilities at school, 6) self-condition. Those six indicators appropriate to the concept of school well-being which is developed by Konu and Rimpela (2002). The concept explains four categories of the school wellbeing, they are school condition (having), social interaction (loving), means for self-fulfillment (being), and health status.

\section{a. Academic Condition of the Students (Having)}

Students feel dissatisfied in schooling if they do not get the knowledge as they expect of. Besides, grade becomes a very important thing for the students' subjective well-being. Students who feel that they have a lot of dissatisfying grades tend to be lazy to go to school. Further, the feeling of school is not fun will grow up on the students who feel left some courses behind other students. 


\section{b. Relationship with Friends (Loving)}

The students who are being comfort with their friends at school tend to be more able to enjoy the process of studying at school, and just the opposite. Besides, the friends' way of making jokes by insulting (such as calling by the physical attribute, humiliating the family's social economic status) can decrease the students' pleasure at school.

\section{c. Relationship with Teachers (Loving)}

Students appraise there always be a fun teacher and a boring teacher. A fun teacher is a teacher whom considered able to communicate to the students, insert a story or an experience when teaching, willing to guide the students without blaming, not easy in giving punishment without hearing the reasons, also giving support not demanding. A teacher on the contrary condition is considered making school is not fun by the students.

\section{d. Activities at School (Having)}

Students consider that the activities at school can be an entertainment when they are feeling bored of the courses. Extracurricular activities offered by the school can attract the students to stand for a long time at school, even some students more enthusiasm to follow the extracurricular activities rather than study in class. However, the condition of extracurricular activities which is sometimes empty makes the students upset.

\section{e. Facilities at School (Having)}

Students consider that one thing which makes the students cannot stand studying at school is the school's facilities. The supporting facilities, such as an uninteresting old building can influence the students' proudness to their school. Students tend to have a big expectation to the facilities provided by the school. The difference between the expectation and the reality decreases the students' enthusiasm to enjoy schooling.

\section{f. Self-Condition (Being)}

The students with low self-esteem, as giving up continuing school to the next class or being graduate from school, feeling inferior to compete to other students, or to their family's social-economic status, tend to less enjoy their days at school.

Thus, the well-being of adolescent students at school in this research can be indicated by the students' perception of the six indicators. Increasingly positive the students' perception of the indicators, it results a good well-being, and also in the opposite. The category of health status did not apply in this research because this is not psychological construct.

\subsection{Rational-emotive approach}

Diener and Biswas-Diener (2003) stated that the subjective well-being is an evaluation result of someone toward his/her life. The evaluation is in form of a cognitive appraisal such as life satisfaction and emotional response of an event, like positive affectation or negative affectation. That cognitive-affective approach is appropriate to psychological concept developed by Albert Ellis, in which he says that psychological disorder is caused by the functions of perception, evaluation, and value system (Koffler, 2005). It means, someone is not influenced by an event but because of his/her perspective and his belief of that event. A disturbing belief is caused by irrational thought that is an evaluation which has characteristics a) rigid and extreme, b) does not match to the reality, c) illogic, and d) has dysfunctional consequence. Rational-emotive approach can make someone happier, by changing the irrational thought to rational thought (Ellis, 2004).

Dryden and Neenan (2004) explained that the rational-emotive approach develop the concept of 
rational/irrational belief that explained through the $\mathrm{ABC}$ model (Activating Events-Beliefs-Consequences) and DE (Disputing-Effect/Energizing) as the intervention process. The stimulus that contributes to the students' problems is called the activating event or A which can be real or imagination but considered true by the students, so that perspective should be respected. The students believe that their reaction to A is a motive of their behaviors and emotions that they feel of, and it is called the consequences, or $\mathrm{C}$ which can impede the development of the students. A and $\mathrm{C}$ are related by belief, or B.

The function of intervention is to dispute or D toward the irrational belief and challenge the students to prove their beliefs. The last step is the effect/energizing, or E in which the students are expected to show the new emotions and behaviors from the result of positive thoughts. When the students have realized that they can change the irrational thoughts to the rational thoughts of their experiences so far at school, so the students can evaluate more positively their life at school. The rational-emotive approach also gives an intervention related to the emotion, such as by relaxation and rational-emotive imagery (Compton, 2005; Brady, 2009). Thus, positive affectation can be more experienced and support the increase of the subjective well-being.

Rational-emotive approach can be a reference in composing a training program (Sharp, 2003). Training in group can be efficient because more than a student can get the benefits, not only from the process but also by seeing other students with the same problems or more serious (Zionts \& Zionts, 1997). In applying the intervention, the basic assumption which held in the rational-emotive approach is someone can change his/her cognitive, emotion, and behavior conditions (Oluyemisi \& Oyesuji, 2013). Ellis suggests using active-directive method (Zionts \& Zionts, 1997) and applying the eclectic techniques as long as it can give positive result (Najafi \& Lea-Baranovich, 2014).

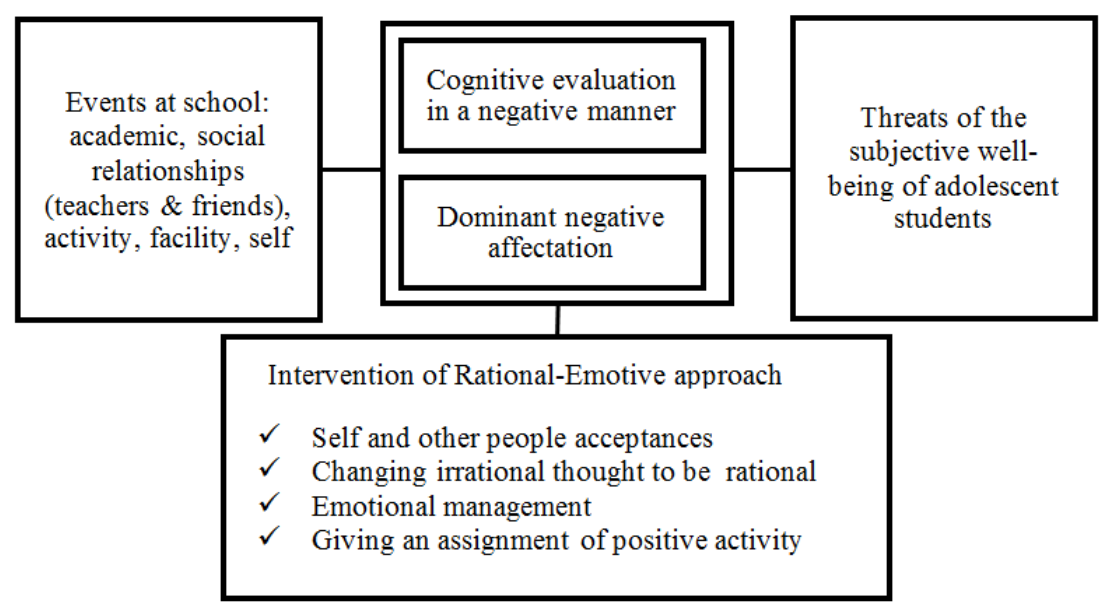

Figure 1. Dynamics of the intervention of subjective well-being increase

\subsection{Purpose of the research and its implications}

This research aimed to find out the influence of the "SENANG" training (acronym of Sekolah Itu Menyenangkan - School is Fun) which based on rational-emotive approach in increasing the subjective well-being of adolescent students (in the age of 15 - 17 years old). Theoretically, this research would give a benefit to develop the theory of subjective well-being of senior high school students, particularly to Indonesian culture. Practically, this research would be useful to overcome the un-disciplinary behavior of the students, the activeness of the students at school, the social relationship of the students, and other problems which are caused by the unenjoyable feeling of the students at school. The hypothesis of this research was the training based on the rational-emotive approach can increase the subjective well-being of adolescent students. 


\section{Methods}

\subsection{Research variables}

Dependent variable in this research was the subjective well-being of adolescent students in senior high school that refers to the theory of subjective well-being by Ed Diener. Subjective well-being is an evaluation result of someone to his/her life cognitively and affectively, that measured by the subjective well-being of adolescent students scale. Independent variable in this research was the "SENANG" (Sekolah Itu Menyenangkan- School is Fun) training. This training was developed according to rational-emotive approach. The core of the rational-emotive theory was there is correlation among cognitive, affective, and behavior in which those three components can be changed more positive (Ellis, 20004).

\subsection{Research design}

As research design, this research used quasi experiment that was the untreated control group design with dependent pretest and posttest samples using double pretest (Shadish, Cook, \& Campbell, 2001).

\subsection{Instruments}

The instrument of this research used the subjective well-being of adolescent students scale developed based on Ed Diener's theory. As content validity, this research used logical validity that was executed through the expert panel by 23 students of Master of Psychology who had passed the course of arranging psychological scale and ever done assistance of Senior High School students, and two educational psychologists. The panel assessment result then be calculated by the formula of Aiken's V (Azwar, 2012) using 5 assessment categories, with minimum coefficient of 0.67 (Aiken, 1985). The panel assessment result on scale items ranged from 0.69-0.87. This scale was experimented to 125 students with the coefficient result of reliability value Alpha Cronbach at 0.937 .

\subsection{Research subject}

This research subjects were 18 students of class X of a public Senior High School A in Yogyakarta as the experimental group, and 18 students of class X of a public Senior High School B in Yogyakarta as the control group. Both of public senior high schools were selected by purposive sampling based on the result of preliminary study and advices from counseling teachers. All of research subjects were in the age range from 15-17 years old had the subjective well-being of adolescent students score in medium category, and willing to participate in this research.

\subsection{Intervention to the experimental group}

The intervention that had been done was in form of a training based on rational-emotive approach named the "SENANG" that is an acronym of "Sekolah itu Menyenangkan"(translated as School is Fun). The training module was composed according to the principles of rational-emotive approach developed by Albert Ellis. The researchers summarized four training sessions based on the rational-emotive approach as follows: 1) Self introduction session, 2) Think rational \& positive session, 3) Emotional management and relaxation session, 4) Evaluation session.

The validity test of the training module content was done through rational analysis qualitatively by a lecturer in cognitive psychology, Dr. Murtini, SU., and a lecturer in psychology who has competence in adolescent students training, Yuli Fajar Susetyo, M. Si. After the validity being clarified, then the training module was tested to 15 students of Public Senior High School C Yogyakarta at the age of 15-17 years old, and could be implemented properly. 


\subsection{Analysis}

The analysis of quantitative data has done to compare the scores of pretest 1 , pretest 2 , and posttest the subjective well-being of adolescent students scale at the experimental group and the control group using Anova Mixed Design by IBM SPSS Statistics 21 program. The qualitative result has done by recording the observation of program implementation and the data of worksheet.

\section{Results}

\subsection{Descriptive stastistical data}

Full descriptive statistical data for each group in every measurement is served at table 1.

\section{Table 1}

The descriptive statistics of each group

\begin{tabular}{llcc}
\hline \multicolumn{1}{c}{ Group } & & Mean & $\begin{array}{c}\text { Standard } \\
\text { deviation }\end{array}$ \\
\hline $\begin{array}{l}\text { Experiment } \\
\mathrm{N}=18\end{array}$ & Pretest I & 179.11 & 10.186 \\
& Pretest II & 183.39 & 13.139 \\
& Posttest & 207.167 & 15.078 \\
Control & & & \\
$\mathrm{N}=18$ & Pretest I & 178.56 & 10.450 \\
& Pretest II & 178.00 & 10.180 \\
& Posttest & 178.83 & 11.723 \\
\hline
\end{tabular}

\subsection{Homogeneity Test}

Before testing the research hypothesis, an analysis was done to find out the homogeneity of covariance scores of the subjective well-being of adolescent students between the experimental group and the control group. The result of homogeneity test Box's M indicated rate $0.051(p>0.05)$ that means the covariance scores of the subjective well-being of adolescent students of both groups were homogeneous.

\subsection{Manipulation Check Test}

This research used two types of manipulation checks. The first manipulation check measures the subject's knowledge related to the rational-emotive approach. The second manipulation check measures the subject ability in applying the rational-emotive approach on the real irrational event at school. The scores of pretest and posttest of manipulation check were analyzed by using wilcoxon signed rank test. Based the analysis result, it was found that all of posttest scores higher than pretest scores. The first and the second manipulation checks had asymptotic significance $=0.000(p<0.01)$. It means there was significant increase on the scores of the knowledge and application of rational-emotive approach after participating the "SENANG" training.

\subsection{Hypothesis Test}

Hypothesis test was done by using mixed anova. The result of research data analysis indicated there was a significant differential score of subjective well-being of adolescent students between the experimental group and the control group $\left(\mathrm{F}_{\text {well-being }}=37.028 ; p<0.01\right)$. It indicated there were interactions among the times (pretest I, pretest II, and posttest). Experimental group indicated the score increase of the subjective well-being of adolescent students after participating the "SENANG" training. The increase could be seen from the data of the average score at the experimental group posttest $\left(\right.$ mean $\left._{\text {experimental }}=207.167\right)$ that higher than the control's $\left(\right.$ mean $\left._{\text {control }}=178.83\right)$. The score of the subjective well-being of adolescent students at the experimental group 
Dewanto, A. C., \& Alsa, A.

had a significant increase with the average dispute of pretest II score and posttest score up to -23.778 . The data showed that the "SENANG" training could increase the subjective well-being of adolescent students at the experimental group significantly. The summary is served at table 2 .

Table 2

The Summary of Hypothesis Test Within-Subject on Subjective Well-Being of Adolescent Student

\begin{tabular}{lcccccc}
\hline \multicolumn{1}{c}{ Source } & $\begin{array}{c}\text { Type III sum of } \\
\text { squares }\end{array}$ & $d f$ & $\begin{array}{c}\text { Mean } \\
\text { square }\end{array}$ & $F$ & Sig. & $\begin{array}{c}\text { Partial eta } \\
\text { squared }\end{array}$ \\
\hline Time & 4267.019 & 2 & 2133.509 & 39.856 & 0.000 & 0.540 \\
Time* Group & 3964.241 & 2 & 1982.120 & 37.028 & 0.000 & 0.521 \\
Error (time) & 3640.074 & 68 & 53.531 & & & \\
\hline
\end{tabular}

\subsection{Continuity Test}

This test aimed to compare the mean difference of each group on every measurement. At the experimental group, the score increase of pretest I and pretest II did not have significant result, whereas the significant result occurs on the score increase of pretest II to posttest. At control group, there were rise and down scores on pretest I, pretest II, and posttest. But the changes were not significant. The effective contribution of the training at the experimental group can be seen from the partial value that was 0.784. It means the "SENANG" training which implemented to the experimental group had a contribution up to $78.4 \%$ toward the change of the subjective well-being of adolescent students. The summary is served at table 3 .

Table 3

The Analysis of Mean Difference of Each Group

\begin{tabular}{|c|c|c|c|c|c|}
\hline Group & $\begin{array}{l}\text { Time } \\
\text { (I) }\end{array}$ & $\begin{array}{c}\text { Time } \\
(\mathrm{J})\end{array}$ & $\begin{array}{c}\text { Mean difference } \\
\text { (I-J) }\end{array}$ & Sig. & $\begin{array}{c}\text { Partial eta } \\
\text { squared }\end{array}$ \\
\hline \multirow[t]{3}{*}{ Experiment } & Pre1 & Pre2 & -4.278 & 0.055 & \multirow{3}{*}{0.784} \\
\hline & & Post & -28.056 & 0.000 & \\
\hline & Pre2 & Post & -23.778 & 0.000 & \\
\hline \multirow[t]{3}{*}{ Control } & Pre1 & Pre2 & 0.556 & 0.798 & \multirow{3}{*}{0.004} \\
\hline & & Post & -0.278 & 0.919 & \\
\hline & Pre2 & Post & -0.833 & 0.731 & \\
\hline
\end{tabular}

The pretest and posttest scores for each aspects of the subjective well-being of adolescent students; that is cognitive and affective were analyzed by wilcoxon signed rank test. Based on the analysis result, it was found out that at the experimental group that both aspects had asymptotic significance $=0.000(p<0.01)$. It means there was a significant increase on the scores of cognitive aspect and affective aspect at the experimental group after participating the "SENANG" training. The influence of "SENANG" training on both aspects of the subjective well-being of adolescent students was quite equilibrate with the average difference was only 0.78 compared to the cognitive aspect. The increase of cognitive and affective aspects were equal because that both aspects have a high relevance (Diener, in Utami, 2009). The contrary result occurs at the control group. The cognitive aspect at the control group had asymp. sig $=0.615(p>0.05)$. while the affective aspect had asymptotic significance $=$ 0.233 ( $p>0.05)$. It means there was not a significant change of the cognitive and affective scores at the control group.

\section{Discussion}

The research hypothesis that proposed was the training based on the rational-emotive approach can increase the subjective well-being of adolescent students. Based on the results have been presented, it can be said that the proposed hypothesis on this research was accepted. The "SENANG" training module was composed based on the theory of rational-emotive approach developed by Albert Ellis. The rational-emotive approach emphasizes on the important of self-acceptance without any requirements (Ellis. 2004). Overcoming the irrational thoughts and 
growing up the rational thoughts and doing emotional management (Ellis, 1980). The researchers provide discussion according to phases of the training program.

\subsection{First phase}

The first phase that was done on the training was giving knowledge about the important meaning of school and the well-being at school. The participants were invited to understand the benefit of attending school and the problems that commonly occurred at school. The participants were asked to write personally about their hopes and the important meaning of school and also their determinations in attending school.

Ellis (1980) stated that developing the anxiety of condition can be done by the formation of objective, in this case the students were directed to see their conditions as students at school is important and to have determinations do their roles as students. Those determinations then become the objectives that will be attained by the participants at school. Koffler (2005) stated that the existence of personal objective can increase the evaluation of life satisfaction. that is the cognitive aspect of subjective well-being. Erylmaz (2011) stated that the subjective well-being can be increased by self-focusing on the future and giving meaning on it. The existence of determinations on the participants in attending school gives a new challenge. The challenge that when they believe that they have resources to attain it can strengthen the positive emotion (Diener, 2003).

\subsection{Second phase}

At the second phase, the participants were invited to identify themselves and accept their conditions. The trainer assisted the students to be brave on admitting their strength and weakness through the game activities and written worksheets. The participants were invited to understand that human-being is unique. Everybody has strength and weakness. No one has identical quality, so that cannot be compared each other. Everybody is worth as him/herself, and accepting self-condition is the best choice. The participants were also invited to give positive perspectives to themselves and other participants, so that it can increase their self-confidences.

Ellis (2004) emphasized the important of acceptances of self, others, and condition. Someone who tends to evaluate negative on him/herself has an irrational thought (Boie, 2014), in which a student focuses on his/her weakness compared to others. In $\mathrm{ABC}$ model, the irrational thought can produce the consequences of negative emotion and unproductive behavior (Jensen, 2008). A student who underestimates him/herself becomes unconfident, whereas confidence positively correlated to the subjective well-being (Diener, in Utami, 2009).

\subsection{Third phase}

The third phase was the comprehension about the cognitive aspect in rational-emotive approach. In this session, the participants were introduced to the $\mathrm{ABCDE}$ model. The participants were invited to understand that their thoughts on the events at school can cause a certain emotion and behavior. The trainer taught the ABCDE model by the HTFR (Happening, Thought, Feeling, and Reaction) diagram approach that easy to understand (Knaus, 2006). The researchers adapted the HTFR diagram into Bahasa as 4P (Peristiwa, Pemikiran, Perasaan, Perilaku) diagram. The participants were also thaught about irrational beliefs (Master, 1987; Ross, 2006).

In this session, the participants were asked to explain their conditions through the 4P diagram on the worksheets, and then discussed together. The participants realized that when they think positive on an event, so they will get more comfortable feeling. The trainer explained that sometimes people cannot change the events, but they always can change their way of thinking as a part of disputing.

The participants were also invited to always do positive evaluation on the occurred events, particularly at school. Generally, the trainer explained the procedures as follow: 1) identifying the existence of irrational thought, 2) looking for the evidence which that thought is irrational based on the negative feeling and the unproductive behavior that appear, 3) stop believing that thought and change it to other thought that makes more 
positive feeling and more productive behavior, 4) Testing whether that new thought is rational based on the positive feeling and the productive behavior that appear. The participants understood that the events which occur at school sometimes does not match to their hopes, but they can be seen by the other positive perspective.

The way of thinking of someone on an event is a form of cognitive evaluation, in which developing the ability to think positive-optimistic is the way to increase the subjective well-being of adolescent students (Erylmaz, 2011). Someone's perspective about the world can influence his/her emotion and the evaluation toward well-being (Diener, Wirtz, Tov, Kim-Prieto, Choi et al., 2009). The rational-emotive approach explicitly views that negative emotion is not caused by the event, but the result of evaluation based on the perspective of someone to the event. To the same event, the individual response can be different, and adolescent student has been trainable to reject the irrational thought (Zionts \& Zionts, 1997).

\subsection{Fourth phase}

The fourth phase was the emotional management phase. In this phase, the participants were invited to identify the positive and negative emotions through sample cases. The trainer explained to the participants that emotion often appears suddenly following the occurred event, but someone still can change the negative emotion to the positive one through several ways. The trainer and the participants practiced doing deep breathing technique (Orfanos, Ellis, \& Johnston, 1999; Chitkara, Van Tilburg, Whitehead, \& Talley, 2006; Wilding \& Milne, 2008), positive affirmation (Cameron \& Green, 2004; Sherman, Bunyan, Creswell, \& Jeremka, 2009), and imagery relaxation (Carter, 2006; Cameron \& Green, 2004; Wilding \& Milne, 2008; Varvogli \& Darviri, 2011). Ellis (1980) stated that there is correlation among thought, emotion, and behavior. On a certain event, someone can be suggested to calm his/her emotional condition before trying to think positive, so the practical techniques of emotional control are very needed.

The emotional condition of someone which is one aspect of the subjective well-being is affective. Diener stated that a good subjective well-being is indicated by the frequent of positive affectation and the infrequent of negative affectation (Kim \& Tov, 2011). The rational-emotive approach gives assistances to the participants to change the negative emotion become more positive. The healthy emotion can encourage problem solution (Koffler, 2005). The reaction is in form of negative emotion on an important event to be handled in order that an individual is not accustomed to self-defeating pattern (Meyer, 1981).

\subsection{Fifth phase}

On the last phase, the participants were accustomed to do positive daily activities through homework. The participants were asked to write three good things that occur and three good deeds that have been done every day for a week. By thus, it was expected that the participants would be accustomed to see something positively. The result of that homework then discussed together and every participant appreciated each other.

Dryden and Neenan (2004) stated that the cognitive and affective changes are influenced by the change of behavior, so that the direction of positive behavior becomes important. Through this assignment, the participants were invited to do positive behavior and give meaning on it, although that is a simple behavior. By thus, the participants understood that the good things are not difficult and crucial. When someone is active in a meaningful activity, so his/her subjective well-being can be risen (Utami, 2009). Diener (in Utami, 2009) stated that the behaviors in socializing, involving in an activity, and altruism activity can give positive emotional experience. Basically, people love when good things happen to themn but sometimes they do not realize that the good things can be in form of simple things that happen in their daily life.

Other important factor is the "SENANG" training was done in group. Every participant was interacted each other in giving the positive feedback. It grew a healthy social relationship among the participants. The social relationship is related to the subjective well-being (Larsen \& Eid, 2008). Besides, through discussion and together activities, the participants developed the close relationship each other, then it stimulated positive 
emotion (Biswas-Diener, Diener, \& Tamir, 2004). Erylmaz (2011) stated that developing close relationship with friends can reduce self-anxiety which is the way to increase the subjective well-being of adolescent.

This research had several restrictiveness. First, the use of non-random technique in placing the research subjects to the experimental group and the control group (research design of quasi experiment). Second, there was not a follow up to know whether the increase that attained by the subjects during the intervention process can be enduring within a certain time. Third, the use of the same scale instruments of the subjective well-being of adolescent students for pretest I, pretest II, and posttest. The use of the same scale can cause testing effect that giving a threat to the internal validity.

\section{Conclusion}

Appropriate to the objectives of this research, the results of the analysis indicate there was the increase of the subjective well-being of adolescent students score at the experimental group after participating the "SENANG" training. The training process brought the participants to more accept themselves, to change the irrational to rational thoughts, and to grow positive affectation related to the experienced events at school. It made the experimental group could be better in evaluating their life at school. After participating the "SENANG" training, all participants asserted that they got the benefits in form of the ability to more accept themselves and to have a positive sight of the experienced events. It had different result at the control group, which there was not a significant change of the subjective well-being of adolescent students score. Thus, the hypothesis of this research was proven, that was the "SENANG" training can increase the subjective well-being of adolescent students. The "SENANG" training gave a contribution up to $78,4 \%$ to the increase of the subjective well-being of adolescent students.

\section{References}

Aiken, L. R. (1985). Three coefficients for analyzing the reliability and validity of ratings. Educational and Psychological Measurement, 45(1), 131-142. http://dx.doi.org/10.1177/0013164485451012

Azwar, S. (2012). Reliabilitas dan validitas [Relibility and validity]. Yogyakarta: Pustaka Pelajar.

Biswas-Diener, R., Diener, E., \& Tamir, M. (2004). The psychology of subjective well-being. Daedalus, 133(2), 18-25. http://dx.doi.org/10.1162/001152604323049352

Boie, A. M. A. (2014). Measuring irrational beliefs across cultures new directions in the rational emotive behavior therapy theory. Unpublished doctoral dissertation, St. John's University, United States.

Brady, T. (2009). Increasing rational thinking of children utilizing the rational emotive education curriculum by untrained instructors in a short-term application. Unpublished doctoral dissertation, Alliant International University, United States.

Cameron, E., \& Green, M. (2004). Making sense of management change. London: Kogan Page.

Carter, E. (2006). Pre-package guided imagery for stress reduction: Initial result. Counseling, Psychotherapy, and Health, 2(2), 27-39.

Chamberlain (1999). An empirical test of rational-emotive behavior therapy's unconditional self-acceptance theory. Unpublished doctoral dissertation. American University, United States.

Chitkara, D, K., Van Tilburg, M., Whitehead, W. E., \& Talley, N. J.. (2006). Teaching Diaphragmatic Breathing for Rumination Syndrome. American Journal of Gastroenterology, 101(11), 2449-2452. http://dx.doi.org/10.1111/j.1572-0241.2006.00801.x

Compton, W. C. (2005). An introduction to positive psychology. Belmont: Thomson Wadsworth.

Diener, E, Suh, E, \& Oishi, S. (1997). Recent findings on subjective well-being. Indian Journal of Clinical Psychology, 24(1), 25-41.

Diener, E. (1984). Subjective well-being. Psychological Bulletin, 95(3), 542-575. http://dx.doi.org/10.1037/0033-2909.95.3.542

Diener, E., \& Lucas, R. E. (2000). Subjective well-being. In M. Lewis \& J. M. Haviland-Jones (Eds.), Handbook of Emotions (pp. 471-484). New York: The Guildford Press. 
Diener, E., \& Biswas-Diener, R., (2003, February 4-5). Findings on subjective well-being and their implications for empowerment. Paper presented at the Workshop on "Measuring Empowerment: Cross-Disciplinary Perspectives", Washington DC.

Diener, E., Wirtz, D., Tov, W., Kim-Prieto, C., Choi, D., Oishi, S., \& Biswas-Diener, R. (2009). New well-being Measures: Short scales to assess flourishing and positive and negative feelings. Social Indicators Research, 97(2), 143-156. http://dx.doi.org/10.1007/s11205-009-9493-y

Dryden, W., \& Neenan, M. (2004). The rational emotive behavioural approach to therapeutic change. London: Sage Publication.

Ellis, A. (1980). Rational-emotive therapy and cognitive behavior therapy: Similarities and differences. Cognitive Therapy and Research, 4(4), 325-340. http://dx.doi.org/10.1007/BF01178210

Ellis, A. (2004). Why rational emotive behavior therapy is the most comprehensive and effective form of behavior therapy. Journal of Rational-Emotive \& Cognitive-Behavior Therapy, 22(2), 85-92. http://dx.doi.org/10.1023/B:JORE.0000025439.78389.52

Eryllmaz, A. (2011). Investigating adolescents' subjective well-being with respect to using subjective well-being increasing strategies and determining life goals. Dusunen Adam: The Journal of Psychiatry and Neurological Sciences, 44-51. http://dx.doi.org/10.5350/DAJPN2011240106

Huebner, E. S., \& Diener, C. (2008). Research of life satisfaction of children and youth: Implications for the delivery of school-related services. In M. Eid, \& R. Larson (Eds.), The science of subjective well-being (pp. 376-392). New York: The Guilford Press.

Jensen, P. E. (2008). Evaluating the ABC model of rational emotive behavior therapy theory: An analysis of the relationship between irrational thinking and guilt. Unpublished masteral thesis, Villanova University, United States.

Kim, Y. H., \& Tov, W. (2011). Cultural processes underlying subjective well-being. In K. Y. Leung, C. Y. Chiu, \& Y.Y. Hong (Eds.). Cultural processes: A social psychological perspective (pp. 154-171). New York: Cambridge University Press.

Knaus, W. J. (2006). Rational emotive education. Retrieved from http://www.rebtnetwork.org/library/Rational_Emotive_Education.pdf

Koffler, A. M. (2005). Perceptions of beliefs in rational emotive theory among college students: a multidimensional scaling analysis. Unpublished doctoral dissertation, Hofstra University, United States.

Konu, A., \& Rimpela, M. (2002). Well-being in schools: a conceptual model. Health Promotion International, 17(1), 79-87. http://dx.doi.org/10.1093/heapro/17.1.79

Larsen, R. J., \& Eid, M. (2008). Ed Diener and the science of subjective well-being. In R. J. Larsen, \& M. Eid (Eds.), The science of subjective well-being. New York: Guilford Publication.

Master, S. (1987). Mood induction using a rational-emotive therapy theory based procedure. Unpublised doctoral dissertation, Temple University, United States.

Meyer, D. J. (1981). Effects of rational-emotive group therapy upon anxiety and self-esteem of learning disabled children. Unpublished doctoral dissertation, Andrews University, United States.

Najafi, T., \& Lea-Baranovich, D. (2014). Theoretical background, trerapeutic process, therapeutic relationship, and therapeutic techniques of REBT and CT; and some parallels and dissimilarities between the two approaches. International Journal of Education and Research, 2(2), 1-12.

Oluyemisi, P., \& Oyesoji, A. (2013). Revisiting rational emotive therapy as a counselling theory in explaining the behaviour modification psychotherapy process. European Journal of Humanities and Social Sciences, 24(1), 1237-1253.

Orfanos, P., Ellis, E., \& Johnston, C. (1999). Effects of deep breathing exercise and ambulation on pattern of ventilation in post-operative patients. Australian Journal of Physiotherapy, 45(3), 173-182. http://dx.doi.org/10.1016/S0004-9514(14)60348-2

Proctor, C. L., Linley, P. A., \& Maltby, J. (2008). Youth Life Satisfaction: A Review of the Literature. Journal of Happiness Studies, 10(5), 583-630. http://dx.doi.org/10.1007/s10902-008-9110-9

Roeser, R. W., Galloway, M., Casey-Cannon, S., Watson, C., Keller, L., \& Tan, E. (2008). Identity representations in patterns of school achievement and well-being among early adolescent girls: 
The "SENANG" training to increase the subjective well-being of adolescent students

Variable- and person-centered approaches. The Journal of Early Adolescence, 28(1), 115-152. http://dx.doi.org/10.1177/0272431607308676

Ross, W. (2006). What is irrational? Retrieved from http://www.rebtnetwork.org/library/ideas.html

Santrock, J.W. (2007). Adolescence (7th ed.). Boston: McGraw-Hill.

Sarjana, T. W. (2005). International standardized school (Sekolah berstandar internasiaonal). Retrieved from http://www.kompas.com/opini/0501/21/074211.htm

Schimmack, U. (2008). The structure of subjective well-being. In M. Eid \& R. Larson (Eds.), The science of subjective well-being (pp. 97-123). New York: The Guilford Press.

Shadish, W. R., Cook, T. D., \& Campbell, D. T. (2002). Experimental and quasi-experimental designs for generalized causal inference. Boston : Houghton Mifflin Company.

Sharp, S.R. (2003). Effectiveness of an anger management training program based on rational emotive behavior therapy (REBT) for middle school students with behavior problems. Unpublished doctoral dissertation, The University of Tennessee, United States.

Sherman, D. K., Bunyan, D. P., Creswell, J. D., \& Jeremka, L. M.. (2009). Psychological vulnerability and stress: The effect of self-affirmation on sympathetic nervous system responses to naturalistic stressor. Health Psychology American Psychological Association, 28(5), 554-562. http://dx.doi.org/10.1037/a0014663

Shoshani, A., \& Steinmetz, S. (2013). Positive psychology at school: A school-based intervention to promote adolescents' mental health and well-being. Journal of Happiness Studies, 15(6), 1289-1311. http://dx.doi.org/10.1007/s10902-013-9476-1

Siswoyo, D. (2007). Arti pendidikan dan batas-batas pendidikan [Educational meaning and educational borders]. In D. Siswoyo (Ed), Ilmu pendidikan (pp. 15-17). Yogyakarta: Universitas Negeri Yogyakarta.

Triandis, H. C. (2000). Cultural syndromes and subjective well-being. In E. Diener, \& E. M. Suh (Eds.), Culture and subjecetive well-being (pp.13-36). Cambridge: The MIT Press.

Utami, M.S. (2009). Involvement in activity and college students' well-being (Keterlibatan dalam kegiatan dan kesejahteraan subjektif mahasiswa). Jurnal Psikologi, 36(2), 144-163.

Varvogli, L., \& Darviri, C. (2011). Stress management techniques: Evidence-based procedures that reduce stress and promote health. Health Science Journal, 5(2), 74-89.

Vazquez, C., Hervas, G., Rahona, J.J., \& Gomez, D. (2009). Psychological well-being and health: Contributions of positive psychology. Annuary of Clinical and health Psychology Journal, 5(1), 15-27.

Wilding, C., \& Milne, A. (2008). Cognitive behavioural therapy. London: McGraw-Hill.

Yadav, G. (2011). A study of subjective well-being and psychological well-being in relation to male and female adolescents. International Referred Research Journal, 2(22), 84-85.

Zionts, P., \& Zionts, L. (1997). Rational emotive behavior therapy with troubled students. Reclaiming Children and Youth, 6(2), 103-108. 
Dewanto, A. C., \& Alsa, A. 